\title{
Role of ECMO in the treatment of respiratory syncytial virus bronchiolitis: a collaborative report
}

\author{
J Y Khan, S J Kerr, A Tometzki, L Tyszczuk, J West, A Sosnowski, D McCrae, C Skeoch, \\ C Davis, R K Firmin, D Field
}

\begin{abstract}
Aim-To report the collaborative experience of extracorporeal membrane oxygenation (ECMO) in the treatment of respiratory syncytial virus (RSV) bronchiolitis between April 1989 and January 1995. Methods-The medical records of patients with confirmed RSV bronchiolitis referred to three centres (Leicester, Glasgow, and Great Ormond Street) were reviewed.

Results-Twenty four infants were identified. Seventeen had been born prematurely (gestational range 23-40 weeks, median 30 weeks). Thirteen infants had been mechanically ventilated after birth and seven of these had evidence of bronchopulmonary dysplasia (BPD). The age of onset of RSV infection varied from three to 64 weeks (mean 17.4 weeks, median 12 weeks). Ventilation before ECMO ranged from one to 16 days and oxygenation indices at the time of referral ranged from 21-73 (mean 39). Ribavirin was used in eight of the 24 patients. Sixteen patients received venoarterial and eight veno-venous ECMO. ECMO hours ranged from 32-647 (median 196 hours). One infant died (survival rate $96 \%$ ). Cranial ultrasound abnormalities were detected in three patients. However, at follow up only one of the 23 survivors had evidence of developmental delay.

Conclusion-A group of paediatric patients in whom ECMO can be of benefit has been identified. The use of ECMO should be considered when other means of support prove unsuccessful.

(Arch Dis Child 1995; 73: F91-F94)
\end{abstract}

Glenfield Hospital and Leicester Royal Infirmary, Leicester

J Y Khan

S J Kerr

J West

A Sosnowski

R K Firmin

D Field

Royal Hospital for Sick Children, Glasgow

A Tometzki

C Skeoch

C Davis

Hospital for Sick Children, London

L Tyszczuk

D McCrae

Correspondence to: Dr D Field, Department of Child Health, Leiceste Royal Infirmary, Infirmary

Square, Leicester LE1 5WW.

Accepted 6 June 1995 hospital. ${ }^{56}$ In less than $3 \%$ of those cases the
In most infants the illness is mild; but in about $40 \%$ of infected infants and children the
lower respiratory tract will be affected. One in
Respiratory syncytial virus (RSV) causes only pathogen in children it is a major respiratory SV is estimatically presents as bronchic of cases of bronchiolitis, overall ${ }^{2}$ and $80 \%$ of cases diagnosed in the first year of life, ${ }^{4}$ with a peak incidence occurring between 2 and 4 condition will be life-threatening ${ }^{6}$ and require intensive care and ventilation.

For previously healthy infants with bronchiolitis the prognosis is uniformly good; and although about $1 \%$ of inpatients require a period of mechanical ventilation for respiratory failure, the overall mortality reported in normal children varies from $<1 \%$ to $2 \% .{ }^{27} 8$ In contrast to previously healthy infants, morbidity and mortality from RSV bronchiolitis are signifcantly higher in special risk groups with underlying cardiopulmonary disorders such as bronchopulmonary dysplasia (BPD), other types of chronic lung disease (for example, cystic fibrosis ${ }^{9}$ ), and congenital heart disease. Infants with immune deficiency disease, a history of prematurity, or young infants under 6 weeks old are also more likely to develop complicated RSV infection with acute respiratory deterioration. Groothius et al reported that about $50 \%$ of children with BPD were admitted to hospital within the first two years, mainly because of viral respiratory infections, of which the respiratory syncytial virus was the commonest pathogen isolated during the winter. ${ }^{10}$ Infants receiving home oxygen during this period or shortly before were at greatest risk. Likewise, patients with congenital heart disease have an increased risk of severe disease with a reported mortality of $37 \%{ }^{11}$ (compared with $1.5 \%$ in those without a cardiac defect); this rises to $73 \%$ in patients with pulmonary hypertension. The mortality from RSV bronchiolitis is also higher in children with primary immune deficiency $(40 \%)$ and in those receiving chemotherapy $(15 \%){ }^{8}$

Extracorporeal membrane oxygenation (ECMO) was introduced to the United Kingdom in 1989, having been available as a mode of life support in the United States for 15 years. Selection criteria in neonates have become more or less uniform in ECMO centres worldwide, but the application of treatment to the non-neonatal population is still very variable. There are no agreed parameters relating to appropriate use of ECMO in this group. As a result many intensive care units in the United Kingdom may not even consider this mode of treatment despite the failure of conventional management. ECMO is an invasive form of treatment and therefore is not undertaken unless other available modes of treatment have been explored. These include mechanical ventilation and the use of the antiviral agent ribavirin. Ribavirin hastened clinical resolution of bronchiolitis in both previously well infants and in those with cardiorespiratory disease in several series, ${ }^{12-16}$ but these findings have been disputed. ${ }^{17-20}$ 
Controversy regarding its use on a routine basis, particularly in low risk infants ${ }^{21}$ has left us with no clear picture of its role in the routine management of RSV bronchiolitis.

In the United Kingdom infants are referred for ECMO as rescue treatment when they prove refractory to maximal conventional management with presumed fatal respiratory failure. We retrospectively report our collaborative experience of ECMO in the treatment of RSV bronchiolitis over a five year period.

\section{Methods}

The medical records of all paediatric patients referred for ECMO at the participating centres between April 1989 and January 1995 were reviewed. A database sheet developed for the study was completed at each ECMO centre for all patients referred with a diagnosis of RSV bronchiolitis. Referral criteria were not based on historically derived predictors of mortality - for example, oxygenation index and alveolar-arterial oxygen gradient - as is normal practice in newborn infants referred for ECMO. Failure to respond to maximal conventional treatment was individually defined by each centre. However, to provide a uniform measure of disease severity an oxygenation index $(\mathrm{OI})^{22}$ was calculated retrospectively for each patient as follows:

$$
\begin{gathered}
\mathrm{OI}=\mathrm{MAP} \times \mathrm{FIO}_{2}(\%) / \text { Postductal } \mathrm{PaO}_{2}(\mathrm{~mm} \mathrm{Hg}) \\
\mathrm{MAP}=\mathrm{PEEP}+\left[(\mathrm{PIP}-\mathrm{PEEP}) \times\left(\frac{\mathrm{IT}}{\mathrm{IT}}+\mathrm{ET}\right)\right]
\end{gathered}
$$

where $\mathrm{MAP}=$ mean airway pressure, $\mathrm{PIP}=$ peak inspiratory pressure, $\mathrm{IT}=$ inspiratory time, PEEP=peak end expiratory pressure, $\mathrm{ET}=$ expiratory time.

Accepted inclusion criteria for the use of ECMO for respiratory failure in neonates were applied - namely, potentially reversible respiratory failure, limited ventilation $(<10$ days $)$ at high airway pressure, no evidence of pre-existing neurological deficit, and no underlying bleeding disorder.

Table 1 Data of RSV infected patients before referral for ECMO, showing gestation, the presence or absence of bronchopulmonary dysplasia (BPD), the age at referral for ECMO, the number of days of conventional ventilation before referral for ECMO, the presence or

\begin{tabular}{|c|c|c|c|c|c|c|}
\hline $\begin{array}{l}\text { Case } \\
\text { No }\end{array}$ & $\begin{array}{l}\text { Gestation } \\
\text { (weels) }\end{array}$ & $B P D$ & $\begin{array}{l}\text { Referral } \\
\text { age (weeks) }\end{array}$ & $\begin{array}{l}\text { Ventilation } \\
\text { (days) }\end{array}$ & Pneumothorax & $O I$ \\
\hline 1 & 31 & + & 16 & 7 & - & 61 \\
\hline 2 & 29 & - & 40 & 7 & - & 37 \\
\hline 3 & 40 & - & 36 & 10 & - & 26 \\
\hline 4 & 31 & - & 16 & 5 & - & 73 \\
\hline 5 & 26 & - & 64 & 8 & - & 26 \\
\hline 6 & 24 & + & 40 & 5 & - & 35 \\
\hline 7 & 24 & + & 26 & 4 & - & 21 \\
\hline 8 & 40 & - & 6 & 5 & - & 49 \\
\hline 9 & 33 & - & 6 & 6 & - & 30 \\
\hline 10 & 40 & - & 10 & 9 & - & 55 \\
\hline 11 & 26 & + & 20 & 2 & - & 32 \\
\hline 12 & 29 & - & 24 & 6 & - & 36 \\
\hline 13 & 40 & - & 3 & 2 & + & 46 \\
\hline 14 & 28 & - & 12 & 14 & + & 44 \\
\hline 15 & 40 & - & 4 & 6 & - & 48 \\
\hline 16 & 31 & + & 12 & 1 & - & 48 \\
\hline 17 & 28 & - & 12 & 4 & + & 28 \\
\hline 18 & 30 & - & 9 & 4 & + & 30 \\
\hline 19 & 29 & + & 12 & 3 & - & 50 \\
\hline 20 & 40 & - & 7 & 12 & - & 27 \\
\hline 21 & 30 & - & 18 & 2 & - & 42 \\
\hline 22 & 23 & + & 14 & 5 & - & 42 \\
\hline 23 & 32 & - & 5 & 16 & - & 29 \\
\hline 24 & 35 & - & 6 & 7 & + & 25 \\
\hline
\end{tabular}
absence of pneumothorax and the oxygenation index (OI)
Table 2 Data of RSV infected patients after ECMO including the mode, duration, time to extubation after decannulation, and outcome

\begin{tabular}{cllcll}
\hline $\begin{array}{l}\text { Case } \\
\text { No }\end{array}$ & $\begin{array}{l}\text { Mode of } \\
\text { ECMO }\end{array}$ & $\begin{array}{l}\text { Duration of } \\
\text { ECMO (hours) }\end{array}$ & $\begin{array}{c}\text { Time (hours) } \\
\text { to extubation }\end{array}$ & Outcome \\
\hline 1 & VA & 200 & 6 & \\
2 & VA & 140 & 96 & \\
3 & VV & 32 & 6 & Survived \\
4 & VV & 192 & 48 & \\
5 & VA & 202 & 24 & Died \\
6 & VV & 123 & 0 & \\
7 & VV & 330 & 336 & \\
8 & VV & 152 & 24 & \\
9 & VA & 138 & 24 & \\
10 & VV & 647 & 216 & \\
11 & VV & 160 & 168 & \\
12 & VA & 140 & 16 & \\
13 & VA & 252 & 24 & \\
14 & VA & 225 & 120 & \\
15 & VA & 228 & 108 & \\
16 & VA & 232 & 72 & \\
17 & VA & 186 & 168 & \\
18 & VA & 217 & 192 & \\
19 & VA & 172 & 264 & \\
20 & VA & 209 & 360 & \\
21 & VV & 237 & 46 & \\
22 & VA & 168 & 37 & \\
23 & VA & 214 & 150 & \\
24 & VA & 178 & 142 & \\
\end{tabular}

A standard ECMO circuit was adopted in each centre. This has been described before. ${ }^{23}$ Cannulation was achieved by surgical cutdown. A continuous heparin infusion maintained an activated clotting time of $180-200$ seconds (initially a stat dose of 50 units heparin/kg followed by $25-100$ units/kg/hour of heparin). Blood and platelet transfusions were given to maintain the haematocrit between 40 and $45 \%$ and platelet count above $10^{6} \times 10^{9} /$. When bypass was established, ventilation was reduced to 'rest settings' - peak pressure $20 \mathrm{~cm} \mathrm{H} \mathrm{H}_{2} \mathrm{O}$, end-expiratory pressure 8-10 $\mathrm{cm} \mathrm{H}_{2} \mathrm{O}$, rate $10 /$ minute and inspired oxygen $21-30 \%$, in order to minimise atelectasis. At the time of referral many of these patients were receiving inotropic support and after the start of ECMO this was quickly weaned to only a low dose of dopamine infusion, to promote diuresis. ECMO allowed intense physiotherapy to be undertaken without compromising the infant's clinical condition. Echocardiography was performed on all patients and cranial ultrasound scanning on those infants with patent anterior fontanelles. Decannulation was performed only after a successful trial off ECMO during which good arterial blood gases were maintained on moderate ventilator settings.

RSV antigen was sought in nasopharyngeal secretions from exfoliated epithelial cells in all patients. The direct immunofluorescence-antibody test was used as this provided the most rapid diagnostic test and has a sensitivity and specificity of greater than $90 \% .^{5}$

\section{Results}

Twenty four patients with confirmed RSV bronchiolitis were identified in three centres during the six year study period. Patient details are shown in tables 1 and 2. Their gestational ages range from 23 to 40 weeks (mean 31.6 weeks, median 30.5 weeks). Thirteen (13/24) patients had been mechanically ventilated after birth with evidence of bronchopulmonary dysplasia in seven ventilated infants. 
Table 3 Neurological outcome in those patients with abnormal cranial ultrasound findings

\begin{tabular}{cll}
\hline $\begin{array}{l}\text { Case } \\
\text { No }\end{array}$ & Ultrasound abnormality & Neurological status \\
\hline 13 & $\begin{array}{l}\text { Bilateral subependymal } \\
\text { haemorrhages (grade 1) }\end{array}$ & $\begin{array}{l}\text { Developmentally normal at } \\
\text { 6 months } \\
\text { Abnormal development - } \\
\text { motor, vision, } \\
\text { ?hydrocephalus. (?related } \\
\text { to prematurity/neonatal } \\
\text { intensive care) }\end{array}$ \\
$\begin{array}{l}\text { Dilated ventricles } \\
\text { No clinical concerns } \\
\text { during/after ECMO } \\
\text { (short follow up of only 1 } \\
\text { month after ECMO) }\end{array}$ \\
\hline
\end{tabular}

The age at onset of RSV infection varied from three to 64 weeks (median 12 weeks). The mean weight on admission was $4.0 \mathrm{~kg}$ (range 2.0-8.4 kg; median weight $3.62 \mathrm{~kg}$ ). The indications for ECMO were: (1) poor oxygenation ( $n=22$; four of whom had pneumothoraces); (2) carbon dioxide retention $(n=1)$; (3) combination of inadequate oxygenation and carbon dioxide retention $(n=1)$.

All patients treated with ECMO were transferred from intensive care units - most from paediatric intensive care units and adult intensive care units (ITU) at teaching hospitals. The remainder were from adult ITUs in district general hospitals. They had been mechanically ventilated for variable lengths of time (mean $6 \cdot 0$ days; median $5 \cdot 5$ days). The mean PIP was $36 \mathrm{~cm} \mathrm{H}_{2} \mathrm{O}(\mathrm{SD}(5 \cdot 5)$ ), mean PEEP was $5 \cdot 8$ $(2 \cdot 2) \mathrm{cm} \mathrm{H}_{2} \mathrm{O}$ and mean airway pressure was $20(4 \cdot 7) \mathrm{cm} \mathrm{H}_{2} \mathrm{O}$. All except one infant were in $100 \%$ oxygen. Arterial blood gas before the start of ECMO averaged $\mathrm{pH} 7.43(0.13)$, $\mathrm{pCO}_{2} 5 \cdot 8(2 \cdot 1) \mathrm{kPa}, \mathrm{pO}_{2} 6 \cdot 8(1 \cdot 53) \mathrm{kPa}$.

No validation of OI has taken place in nonneonates. ${ }^{24}$ In our sample the mean OI was 39 (range 21 to 73 ); this was used to quantify problems of oxygenation. We have not attempted to describe increasing evidence of barotrauma at the time of referral, but pneumothoraces were seen in five patients before ECMO and in one patient after ECMO, and these required between one and five chest drains. Ribavirin had been used in eight of 24 patients.

Sixteen patients received veno-arterial and eight veno-venous ECMO. The duration of ECMO varied from 32 hours to 647 hours (median 196 hours). Nineteen infants have been followed up for more than one year and satisfactory neurological outcome confirmed in all except case 17 (table 3). Five infants remain less than one year from completion of their ECMO course. However, none of these is giving cause for concern. Cranial ultrasound abnormalities were identified in only three patients (table 3 ). The median time to extubation was 82 hours (range 6 to 360 hours). One (1/24) patient died (survival rate $96 \%$ ).

\section{Discussion}

ECMO has been an established mode of treatment for neonates with severe cardiorespiratory failure in the United States for the past 15 years. However, its use in providing respiratory support in non-neonates, although increased in recent years, still remains uncommon. The final decision to refer for ECMO for our patients was based on clinical judgment. In general, the combination of deteriorating respiratory failure in spite of vigorous ventilatory support in a child with an obstructive airway disease and haemodynamic instability formed the basis of that decision. OI has proved a useful indicator for the use of ECMO in neonates as respiratory failure in newborns is usually secondary to alveolar disease and/or pulmonary hypertension. In children the pathogenesis is more heterogenous, often comprising both airway and alveolar problems, as in the patients presented here.

Infection with RSV is a major cause of admission to hospital during the winter months in temperate climates, and the mortality in those requiring intensive care is low. ${ }^{27}$ However, some infants with specific risk factors tend to have more severe respiratory problems when they present with RSV infection.

Eighteen of the 24 patients presented here had been premature of whom 13 had been ventilated in the neonatal period; seven had documented evidence of bronchopulmonary dysplasia (BPD). One patient had congenital heart disease (mitral regurgitation). Therefore, about $80 \%$ of patients referred for ECMO fell into special risk groups associated with more severe forms of RSV infection. Mortality among these groups when infected with RSV has been reported to be as high as $40 \% .^{811}$

Meert et $a l^{25}$ compared previously healthy prematurely born infants with full term infants admitted to hospital with RSV infection, and evaluated the role of prematurity on the clinical course of the illness. She found that premature birth by itself increased the risk of more severe and prolonged RSV disease. Infants who had been born prematurely developed a greater degree of respiratory insufficiency and subsequently, there was greater need for supplemental oxygen and/or mechanical ventilation. Meert further suggested that because of their smaller size and consequently smaller airway, there was a potential for increased airway resistance, hence the development of respiratory insufficiency.

Lebel et $a l,{ }^{26}$ however, reported that the increased severity of RSV infection in such infants was associated with their postconceptual age rather than smaller size, because younger infants have less physiological respiratory reserve compared with matched low weight older infants. Groothuis et $a l,{ }^{10}$ in a prospective study of the natural history of RSV infection in children with BPD, found that more than two thirds of these children required admission, which was generally more prolonged (exceeding seven days, whereas the hospital stay for an otherwise normal infant with RSV infection was four to seven days), and associated with significant morbidity (although there were no deaths among the study population).

Our data seem to confirm that prematurity and bronchopulmonary dysplasia do predispose 
infants to severe problems when infected with RSV. The duration of ECMO was not influenced by gestation at birth nor previous history of BPD. Moreover, pre-existing chronic lung disease did not necessarily predict a poor outcome in that six of the seven patients survived. We also found that neither a high OI nor long ventilation before ECMO were reliable predictors of the duration of ECMO and did not correlate with survival.

Most (66\%) of patients in our study received veno-arterial (VA) support. Traditionally this has been the preferred mode of support in these haemodynamically unstable children in that it provides cardiovascular as well as respiratory support, requires a shorter operating time, and hence, stabilisation is quickly achieved. However, its disadvantages include carotid artery ligation and the risk of perfusing air bubbles or particles directly into the arterial system. Veno-venous ECMO has the advantage of sparing the carotid artery, but this technique can only be used on selected patients because of the longer operative time required to place the cannulae. Where veno-venous ECMO has been established using two separate cannulae, subsequent problems with poor healing of the groin wound and persistent leg swelling have caused concern. These complications have been resolved by the introduction of a double-lumen veno-venous catheter which provides access for drainage and perfusion. This is much less invasive but is more technically demanding to place satisfactorily.

The duration of ECMO was considerably longer in this population (mean 207 hours) compared with the neonatal population in whom ECMO hours averaged 120. Case 10 had an extremely prolonged course of venovenous extracorporeal life support (27 days) this was a cardiac patient who had developed RSV bronchiolitis six days after mitral valve replacement, and the outcome was favourable.

It is encouraging that these infants generally had good neurological outcomes, with developmental delay documented in only one infant - an ex-premature (28 weeks' gestation) infant who had required intensive care support during the neonatal period, and was known to have dilated ventricles before referral.

ECMO entry criteria have been inadequately defined for the non-neonatal population and therefore tend to be specific to the institution. Ventilatory support before ECMO was considered optimal by referring teams, and although blood gases showed normal mean $\mathrm{pH}$ and $\mathrm{pCO}_{2}$, it must be emphasised that high mean airway pressures $\left(20(4 \cdot 7) \mathrm{cm} \mathrm{H}_{2} \mathrm{O}\right)$ and $100 \%$ inspired $\mathrm{O}_{2}$ were used to achieve $\mathrm{PaO}_{2}$ $6.8(1.5) \mathrm{kPa}$. Haemodynamic instability was also a significant contributing factor in referral of these patients for ECMO, many of whom were receiving inotropic support. Therefore, all patients referred to our centres for ECMO were deemed unsalvageable with maximal conventional management and $96 \%$ ultimately survived with the use of ECMO. We believe that we have identified a group of paediatric patients in whom this form of intervention can be of benefit with excellent neurological outcome and long term survival.

The United Kingdom is currently undertaking a randomised trial of ECMO compared with conventional ventilation in newborn infants. Because only small numbers of children reach ECMO criteria following RSV infection, a similar study in this population is not practical. The results presented here indicate that the use of ECMO should at least be considered when other means of support are proving unsuccessful.

1 Panitch HB, Callahan CW, Schidlow DV. Bronchiolitis in children. Clin Chest Med 1993; 14: 715-31.

2 Price JF. Acute and long-term effects of viral bronchiolitis in infancy. Lung 1990; suppl: 414-21.

3 Henderson FW, Clyde WA, Collier AM, Denny FW, Senior RJ, Sheaffer CI, et al. The etiologic and epidemiologic spectrum of bronchiolitis in pediatric practice. $₹$ Pediat 1979; 95: 183-90.

4 Parrott RH, Kim HW, Brandt CD, Chanock RM. Respiratory syncytial virus in infants and children. Prev Med 1974; 3: 473-80.

5 LaVia WV, Marks MI, Stutman HR. Respiratory syncytial virus puzzle: clinical features, pathophysiology, treatment and prevention. F Pediatr 1992; 121: 503-10

6 Dawson K, Kennedy D, Asher I, Cooper D, Cooper P, Francis P. The management of acute bronchiolitis. f Paediatr Child Health 1993; 29: 335-7.

7 Jaimovich D, Kecskes SA. Management of reactive airway disease. Progress Ped Crit Care 1992; 8: 147-62.

8 Hall CB, Powell KR, McDonald NE, Gala CL, Menegus ME, Suffin SC. Respiratory syncytial virus infection in children with compromised immune function. $N$ Engl $f$ Med 1986; 315: 77-81.

9 Abman SH, Ogle JW, Butler-Simon N Rumack CM, Accurso FJ. Role of respiratory syncytial virus in early hospitalizations for respiratory distress of young infants with cystic fibrosis. F Pediatr 1988; 113: 826-30.

10 Groothuis JR, Gutierrez KM, Lauer BA. Respiratory syncytial virus infection in children with bronchopulmonary tial virus infection in children with
dysplasia. Pediatr 1988; 82: $199-203$.

11 McDonald NE, Hall CB, Suffin SC, Alexon C, Harris PJ, Manning JA, et al. Respiratory syncytial virus infection in infants with congenital heart disease. $N$ Engl F Med 1982; 307: 397-400.

12 Smith DW, Frankel LR, Mathers LH, Tang ATS, Ariagno RL, Prober CG, et al. A controlled trial of aerosolised ribavirin in patients receiving mechanical ventilation for severe respiratory syncytial virus infection. $N$ Engl $\mathcal{f} \mathrm{Med}$ 1991; 325: 24-9.

13 Hall CB, McBride JT, Gala CL, Hildreth SW, Schabel KC. Ribavirin therapy of respiratory syncytial virus infection in infants with underlying cardiopulmonary disease. $\mathfrak{f} A M A$ 1985; 254: 3047-51.

14 Taber LH, Knight V, Gilbert BE, McLung HW, Wilson SZ, Norton HJ, et al. Ribavirin aerosol treatment of bronchiolitis associated with respiratory syncytial virus infecchiolitis associated with respiratory syncytial
tion in infants. Pediatrics $1983 ; 72: 613-8$.

15 Barry W, Cockburn F, Cornall R, Price JF, Sutherland G, Vardag A. Ribavirin aerosol for acute bronchiolitis. Arch Dis Child 1986; 61: 593-7.

16 Rodriguez WJ, Kim HW, Brandt CD, Schwartz RH, Gardner MK, Jeffries B. Aerosolized ribavirin in the treatment of patients with respiratory syncytial virus disease. Pediatr Infect Dis 1987; 6: 159-63.

17 Khan A, Moler F, Custer J, Shope T. Respiratory syncytial virus related morbidity and mortality before and after ribavirin introduction. Am Rev Respir Dis 1991; 143: A510.

18 Wald ER, Dashefsky B, Green M. Ribavirin: a case of premature adjudication. $\mathcal{F}$ Pediatr 1988; 112: $154-8$.

19 Snell NJC. Ribavirin in respiratory syncytial virus infection. Arch Dis Child 1988; 63:986-90.

20 Rakshi K, Couriel JM. Management of acute bronchiolitis. Arch Dis Child 1994; 71: 463-9.

21 Milner AD. Acute bronchiolitis in infancy. Curr Paediatr 1992; 2: 46-9.

22 Stolar CJH, Snedecor SM, Bartlett RH. Extracorporeal membrane oxygenation and neonatal respiratory failure: experience from the Extracorporeal Life Suppor Organization. F Pediatr Surg 1991; 26: 563-71.

23 Pearson GA, Field DJ, Firmin RK, Sosnowski AS. UK experience in neonatal extracorporeal membrane oxygenation. Arch Dis Child 1992; 67: 822-5.

24 O'Rourke PP, Stolar CJH, Zwischenberger JB, Snedecor SM, Bartlett RH. Extracorporeal membrane oxygenation: support for overwhelming pulmonary failure in the pediatric population. Collective experience from the pediatric population. Collective experience from the 1993; 28: 523-9.

25 Meert K, Heidemann S, Abella B, Sarnaik A. Does prematurity alter the course of respiratory syncytial virus infection? Crit Care Med 1990; 18: 1357-9.

26 Lebel MH, Gauthier M, LaCroix J, Rousseau E, Buithieu M. Respiratory failure and mechanical ventilation in severe bronchiolitis. Arch Dis Child 1989; 64: 1431 . 